ISSN 0001-6002/2010/52=1/26-29 Acta Médica Costarricense, (C2010

Colegio de Médicos y Cirujanos

\section{Ten-year Experience with Minimally- invasive Thoracic Surgery at the Hospital Dr. Rafael Ángel Calderón Guardia}

\author{
(Ten-year Experience with Video Assisted Thoracic Surgery)
}

José Alberto Mainieri-Hidalgo

\section{Abstract}

Objective: To analyze how useful has been the development of thoracoscopy at the Hospital Dr. Rafael A. Calderón Guardia Hospital.

Materials and methods: With the purpose of assessing the experience acquired with the practice of minimally-invasive thoracic surgery (VAT surgery) during the first 10 years; clinical data from March 1999 to March 2009 of 788 patients, taken from a database of the Thoracic Surgery Department, was reviewed.

Results: During this 10-year period, $25 \%$ of the Department's surgical procedures were performed through thoracoscopy. This percentage increased to $49 \%$ during the last 2 years of the reviewed period. The medical records of patients that underwent diagnostic procedures or tumor resections were analyzed. Diagnosis was obtained in $97.4 \%$ of patients that underwent surgery with the purpose of diagnosis; mediastinal tumors were the most difficult to diagnose, in two of these cases, the pathologist requested a larger sample. No major procedures were performed through this method. There were no mortality cases. The conversion rate was $2.6 \%$, of which $20 \%$ was due to bleeding and $80 \%$ to perform a major procedure.

Conclusion: Thoracoscopy has revolutionized the field of medicine, superseding previous approaches, such as toracotomy, for minor surgeries; this has allowed the performance of complex surgeries and procedures. The results obtained show satisfactory results for patients and usefulness for the institution.

Key words: Thoracoscopy, VATS surgery, hyperperhidrosis, neumothorax, mesothelioma, empyema.

Received: 28 July 2009 Accepted: 29 September 2009
Thoracic Surgery Department, Hospital Dr. Rafael A. Calderón Guardia Contact information:

E-mail: mainierijose@ hotmail.com 
Thoracoscopy is a surgical procedure described by Jacobaeus in $1910 .{ }^{1}$ Its use was mainly as a

diagnostic method. It was also utilized as treatment for tuberculosis, to remove pleural adhesions and to collapse the lung. With the development of antiphymic drugs, the treatment fell into disuse. In 1973, DeCamp and colleagues called back attention to the procedure by publishing their experience as a diagnostic method at the Ochsner Clinic. ${ }^{2}$ Since then, and parallel to the technological development of video-assisted endoscopy, of coagulating instruments, staplers and others; a point has been reached were an important rate of thoracic surgery is performed in a minimally-invasive manner, assisted by thoracoscopy. This method allows inspection of the pleura, the lung, the mediastinum, the pericardium, the chest wall and the diaphragm; to obtain biopsies from tissues, tumors and adenomegalies; in order to remove some injuries caused by this and other procedures.

The following are among the most useful indications for thoracoscopy:

a) Surgical treatment of several sympathetic system disorders such as: hyperhydrosis, reflex sympathetic dystrophy, Reynard's phenomenon and facial flush. It has become one of the most frequent surgeries, since it is possible to make two very small surgical incisions and with important advantage for the patient. $^{3-5}$

b) Management of organized pleural effusion and empyema is also possible through this method, because it allows the break up of fibrin blocks, complete drainage, to observe the presence of other injuries and to directly take a biopsy. Moreover, it is possible to produce pleurodesis by irritating the pleura, mechanically or with a substance, or by removing it. 6,7

c) It is very useful for the management of malignant pleural effusion because it allows assessment of the cavity, to drain the effusion, obtain biopsies under direct vision, and to provoke pleurodesis by talc poudrage, scraping the pleura or by parietal pleurectomy. 8,9

d) It is the ideal procedure to perform lung biopsies and resection of pulmonary nodules, even when malignancy is suspected. The frozen biopsy allows the continuation of the prescribed oncologic surgery at that same time. ${ }^{10,11}$ e) In the majority of cases, resection of blebs for the treatment of spontaneous pneumothorax can be performed through this method, with the aid of staplers; and at the same time, carry out pleurodesis. $^{12-15}$

f) Resection of pleural and mediastinal tumours ${ }^{16,17}$, diaphragm plication and other more advanced procedures, such as lobectomy, pneumonectomy and esophagectomy; according to each center's experience. $^{18,19}$

\section{Materials and Methods}

This is a case analysis retrospective observational study, for which the data base from the Servicio de Cirugía de Torax (Thorax Surgery Department) of Hospital Dr. Rafael Ángel Calderón Guardia was used. The clinical cases of patients that underwent a thoracoscopy, from its starting point in March 1999 to date, were studied.

After approval by the Hospital's Scientific Ethics Committee (DM 7491), the medical records of patients that underwent diagnostic procedures were reviewed with the purpose of verifying the thoracoscopy's results when used to diagnose injuries that, otherwise, would have required a thoracotomy. The same was done with those that underwent surgery for lung, chest wall, diaphragm or mediastinal tumor resection; in order to access the procedure's effectiveness.

\section{Results}

During the first 10 years of thoracoscopy's use in the HCG, 788 minimally invasive surgeries were performed. This represents $25 \%$ of total surgeries performed during the reviewed period, increasing to $49 \%$ during the last two years, in which 278 VATs were performed.

The procedures performed are shown in Table 1; sympathetic system surgery was the most frequent one, followed by lung and mediastinal biopsies for histological diagnosis of primary or metastatic neoplasm, and lung decortication due to empyema.

The frequency with which a diagnosis was achieved in procedures with that purpose was $97.4 \%$; these are shown in Table 2. 
The conversion rate was $2.6 \%, 80 \%$ due to technical difficulties and $20 \%$ to bleeding. Technical difficulties were: impossibility to remove a tumor due to its size or location; prescription of lobectomy or pneumonectomy, and in two cases, it was not possible to identify the injury through thoracoscopy.

There was no mortality. No major resections were practiced, such as lobectomies or pneumonectomies. There was no massive bleedings or infections in the incisions at the ports of entry. Post-operatory pain was not objectively comparable to that of thoracotomies because in these an epidural catheter is used for pain management. Post-operatory hospitalizations were not comparable either due to the system's characteristics. Several cases which could have been performed through thoracoscopy, especially those of lung biopsy for interstitial pneumopathy, were not, due to lack of availability of staplers.

\section{Discussion}

VAT has revolutionized in a very important way thoracic surgery, which has been traditionally stigmatized due to the harshness of the approaches to the thoracic cavity. Through two or three half to one centimeter or more incisions when a tumor had to be removed, it was possible to perform up to $49 \%$ of total surgeries at Hospital Dr. Rafael Ángel Calderón Guardia, during the last two years.

Table 1. Procedures practiced through thoracoscopy, from March 1999 to March 2009

Procedure

\begin{tabular}{lcc}
\hline Simpathetic system & 513 & $65.1 \%$
\end{tabular}

surgery

$\begin{array}{lll}\text { Lung decortication } & 60 & 7.6 \%\end{array}$

Lung biopsy

Pleura biopsy

Lung wedge resection

Mediastinum biopsy

Resection of blebs

Hemothorax drainage

51

$6.5 \%$

$44 \quad 5.6 \%$

Pericardiotomy

Diaphragm surgery

Chest wall tumor resection

Mediastinal tumor

32

$4.1 \%$

24

$3.1 \%$

$22 \quad 2.8 \%$

$18 \quad 2.3 \%$

$7 \quad 0.9 \%$

$6 \quad 0.8 \%$

$4 \quad 0.5 \%$

resection

$\begin{array}{lll}\text { Exploratory thoracoscopy } & 3 & 0.4 \%\end{array}$

\begin{tabular}{|lcc|} 
Vagectomy & 1 & $0.2 \%$ \\
\hline Total & 788 & 100
\end{tabular}

\begin{tabular}{|c|c|c|c|}
\hline Biopsy & Cases & Diagnosis & Rate \\
\hline Lung & 51 & 51 & $100 \%$ \\
\hline Pleura & 44 & 43 & $97.7 \%$ \\
\hline Mediastinum & 24 & 22 & $91.7 \%$ \\
\hline Total & 119 & 116 & $97.4 \%$ \\
\hline
\end{tabular}

The approach resulted in a solution to the problem of $96.6 \%$ (496 out of 513) of the patients with problems in the sympathetic system of hyperhidrosis, facial flush, reflex sympathetic dystrophy, Raynaud. As a secondary observation, four patients with hypertension that underwent surgery for hyperhidrosis, returned to normality afterwards. ${ }^{20}$ In three cases of severe compensatory sweating, the procedure had to be reversed by removing the staples and returning the patient to its initial condition. In two of the seven cases of patients with Raynaud that underwent surgery, there were no satisfactory results; however in one of them, there was moderate improvement.

One of the main useful features was the possibility to solve fluid accumulation within the pleural space, such as coagulated hemothorax, especially in septic patients' emphyemas, with a compromised general condition and which got infected or fistulated with some frequency through the incisions. The sooner the procedure was practiced, the higher the probability to drain the empyema and decorticate the lung to expand it.

For the management of malignant pleural effusions, thoracoscopy is practiced to obtain visually oriented biopsies, to drain the pleural space and induce pleurodesis by talc poudrage or by practicing pleurectomy.

The possibility of obtaining biopsies from intrathoracic injuries of the lung, the pleura, or the mediastinum with a high effectiveness rate; $97.4 \%$ in this study, has truly represented a significant change for patients.

The resection of pediculated tumors from the chest wall was not complex in four cases and in the majority of small and peripheral lung tumors. Major resections are not practiced yet by the group, such as lobectomies or pneumonectomies Mediastinal tumors required more work due to the learning curve and the necessary caution to prevent damage of vascular structures.

Thoracoscopy has revolutionized thoracic surgery, particularly in the case of minor procedures, which in the past required a thoracotomy. The 
incorporation of video has allowed more complex surgeries to be performed. With experience and availability of equipment and resources, it could broaden to almost all procedures. Today a thoracotomy is not justified in order to get a diagnosis or for resection of peripheral nodules, except for selected cases or when thoracoscopy failed. It is necessary to promote formal training to introduce major procedures, such as lobectomy, pneumonectomy and esophagectomy.

\section{References}

1. Jacobaeus HC. Ueber die Moglichkeit die Zystoskopie bei Untersuchung seroser Honlungen anzuwenden. Munchen Med Wehenschr. 1910; 57:2090-2092.

2. DeCamp PT, Mosely PW, Scott ML. Diagnostic thoracoscopy. Ann Thorac Surg. 1973; 16: 79-84.

3. Doolabh N, Horswell S, Huber L, Williams M, Huber L, Prince S, Meyer DM, Mack MJ. Thoracoscopic sympathectomy for hyperhidrosis: indications and results. Ann Thorac Surg. 2004; 77:410-404.

4. Chamorro R, Garita E, Mainieri JA, Miranda J, Robelo B, Salazar C. Tratamiento de la hiperhidrosis mediante simpatectomía torascópica. Experiencia en Costa Rica. Rev Med Broncopul. 2006; 3:35-37

5. Chamorro R, Robelo B, Garita E, Miranda J, Mainieri JA, Salazar C. Hiperhidrosis primaria, tratamiento mediante simpatectomía por videotorascopia. Act Médic Costarric. 2006; 48:190-193.

6. Sendt W, Foster E, Hau T. Early thoracoscopic debridement and drainage as a definite treatment for pleural empyema. Eur J Surg. 1995; 161: 73-76.

7. Landreneau RJ, Keenan RJ, Hazalrigg SR, Mack MJ, Naunheim KS. Thoracoscopy for empyema and hemotórax. Chest. 1995; 109: 18-24.

8. Viallat JR, Rey F, Astoul P, Boutin Ch. Thoracoscopic talc poudrage pleurodesis for malignant effusions. A review of 360 cases. Chest. 1996; 110:1387-1393.

9. Colice GL, Curtis A, Deslauriers J, Heffner J, Ligth R, Littenberg B, Sahn S, Weinstein KA, Yusen RD. Medical and surgical treatment of parapneumonic effusions. An evidence-based guideline. Chest. 2000; 118:1158-1171.

10. Miller DL, Allen MS, Trastek VF, Deschamps C, Pairolero PC. Videothoracoscopic wedge excision of the lung. Ann Thorac Surg. 1992; 54: 410-414.

11. Carballo M, Maish M, Jaroszewski D, Holmes CE. Videoassisted thoracic surgery (VATS) as a safe alternative for the resection of pulmonary metastases: a retrospective cohort study. J Cardiothorac Surg. 2009; 4:1-13.

12. Wakabayashi A, Brenne M, Wilson AF. Thoracoscopic ablation of blebs in the treatment of recurrent or persistent spontaneous pneumothorax. Ann Thorac Surg. 1989; 48: 651-653.
13. Melvin WS, Krasna MJ, Mc Laughlin JS. Thoracoscopic management for spontaneous pneumothorax. Ann Thorac Surg. 1992; 103: 1877-1879.

14. Walter DA, Forty J PW, Morritt GN. Video-assisted thoracoscopic surgery versus thoracotomy for spontaneous pneumothorax. Ann Thorac Surg. 1994; 58: 372-276.

15. Kim KH, Kim HK, Han JY, Kim JT, Wen YS, Choi SS. Transaxillary minithoracotomy versus video-assisted thoracic surgery for spontaneous pneumothorax. Ann Thorac Surg. 1996; 61: 1510-1512.

16. Takahama M, Kushibe K, Kawaguchi T, Kimura M, Taniguechi S. Video-assisted thoracoscopy surgery. Is a promising treatment for solitary fibrous tumor of the pleura. Chest. 2004; 125: 1144-1147.

17. Mainieri JA, Putvinsky V, Mainieri G. Mesotelioma pleural en Costa Rica. Acta Méd Costarric. 2006; 48: 24-29.

18. Tomaszek SC, Cassivi SD, Shen KR, Allen MS, Nichols AC, Deschamps C, Wiglie DA. Clinical Outcomes of videoassisted thoracoscopy lobectomy. Mayo Clinic Proc. 2008; 84: 509-513.

19. Udawa H, Ueno M, Kinoshita Y. Rationale for videoassisted radical esophagectomy. Gen Thorac Cardiovasc Surg. 2009 57: 127-131.

20. Chou SH, Kao EL, Lin CHCH, Chuang HY, Huang MF. Sympathetic hypertensive syndrome: a possible surgically curable type of hypertension. Hypertens Res. 2005; 28: 409514.

\section{Translated by: Natalia Porras}

